\title{
Calcification of the Renal Vein and Inferior Vena Cava on a Renal Tumor: An Exceptional Case
}

\section{Noël Coulibaly¹, Evrard Yao1, Fatoumata Ouattara-Cissé1, Tawakaltu Bolasade Adebayo1, Servais Sai ${ }^{2}$, Lamine Bamba', Koffi Djè̀ ${ }^{3}$}

${ }^{1}$ Urology Department of Treichville University Hospital, Abidjan, Côte d'Ivoire

${ }^{2}$ Department of Anaesthesia and Intensive Care, Treichville University Hospital, Abidjan, Côte d'Ivoire

${ }^{3}$ Urology Department of Bouaké University Hospital, Bouaké, Côte d’Ivoire

Email: coulny@gmail.com

How to cite this paper: Coulibaly, N., Yao, E., Ouattara-Cissé, F., Adebayo, T.B., Sai, S., Bamba, L. and Djè, K. (2021) Calcification of the Renal Vein and Inferior Vena Cava on a Renal Tumor: An Exceptional Case. Open Journal of Urology, 11, 413-419. https://doi.org/10.4236/oju.2021.1111040

Received: September 29, 2021

Accepted: November 20, 2021

Published: November 23, 2021

Copyright $\odot 2021$ by author(s) and Scientific Research Publishing Inc. This work is licensed under the Creative Commons Attribution International License (CC BY 4.0).

http://creativecommons.org/licenses/by/4.0/

\begin{abstract}
Background: A thrombus of the inferior vena cava and renal vein makes the management of renal cancer more difficult. Aim: The aim is to highlight and discuss the management of a case of renal cancer with an unusual thrombus in our context. Case Presentation: We report the case of a 49 -year-old female with left kidney cancer, complicated by a calcified thrombus of the renal vein and inferior vena cava. A calcification of renal vein and vena cava was discovered during surgery, even though the diagnosis prior to surgery was a renal tumor with partial thrombus of the IVC. We performed a thrombectomy and left nephrectomy. The post-operative course was marked by the death of the patient a month later. Conclusion: Renal vein and inferior vena cava (IVC) calcifications are uncommon. Preoperative diagnosis is difficult but guided by medical imaging. Renal cancer is one of the causes. A thrombus or calcification of the vena cava worsens the prognosis of cancer.
\end{abstract}

\section{Keywords}

Renal Cell Carcinoma, Inferior Vena Cava Thrombus, Thrombectomy

\section{Introduction}

Most renal tumors are cancers. Renal cancer is the third urological cancer after prostate and bladder and represents about 3\% of adult cancer. Due to the anatomic position of the kidney, renal cancer has a long latency, and the discovery is done luckily during investigations for another reason. Most of the time it is done at a metastatic stage. During its progression, cancer will cross the kidney capsule, 
invade peri renal fat and spread into lymph nodes, renal vein and inferior vena cava (IVC). A thrombus of the IVC during the course of renal cancer is infrequent $(2-10 \%)$. The occurrence of calcification of the inferior vena cava (IVC) with a kidney tumor is more difficult to find [1] [2]. Few cases have been reported in literacy. In Côte d'Ivoire, no case has been previously reported. We are presenting the case of a patient whose IVC calcification was suspected by the computed tomography scan and confirmed during the surgery. The aim of this report was to emphasize the morbidity and mortality and difficult management of such cases in the underequipped area. Informed consent was obtained from the family to report this case.

\section{Case Report}

The patient was a 49 years old female, known to be hypertensive and was being followed. She came to us with an abdominal mass. The onset of the signs occurred about 4 months ago, with a progressive worsening left lumbar pain. It was described as a permanent constriction, with a paroxysmal episode, without any triggering factor or objective sedation. There was no hematuria or burning of the urine. She consulted a community health centre where the diagnosis of lumbar osteoarthritis was made, with the introduction of analgesic treatment. Given the persistence of the signs, she consulted a private care unit where scannographic and biological explorations were performed. She was then referred to us for care.

She had a major history of undocumented exploratory laparotomy. There was no notion of previous nephropathy or exposure to hydrocarbons. We also noted the absence of personal or familial venous thromboembolic disease. She had 4 children. She was menopausal without any notion of metrorrhagia.

On admission, she was vigilant, with a WHO score of 1 . The conjunctiva were stained, there was no edema of the lower limbs. Blood pressure was 140/100 mmHg with a pulse rate of 79/minute. There was a median laparotomy scar. The urogenital examination showed a left lumbar curvature with lumbar contact and kidney swelling. The rest of examination was unremarkable. We concluded that it was a left renal tumor syndrome.

Computed tomography scan coupled with study of the kidney vessels objectified a hypervascular tumor of the lower pole of the left kidney with thrombus of the left renal vein and IVC. The upper pole of the thrombus was calcified and its upper level was located at the junction of the suprahepatic veins, corresponding to a level III of the MAYO classification. In addition, a dilatated left gonadal vein was noted (Figure 1 and Figure 2).

An anticoagulant treatment with low-molecular-weight heparin at a curative dose was instituted preoperatively for 5 days. Our surgical attitude was sequenced as follows. We approached this tumor with a xyphopubic laparotomy. After detachment of the right Toldt fascia (Figure 3), the IVC was exposed from the confluence of the iliac veins to the subhepatic portion of the renal vessels. 


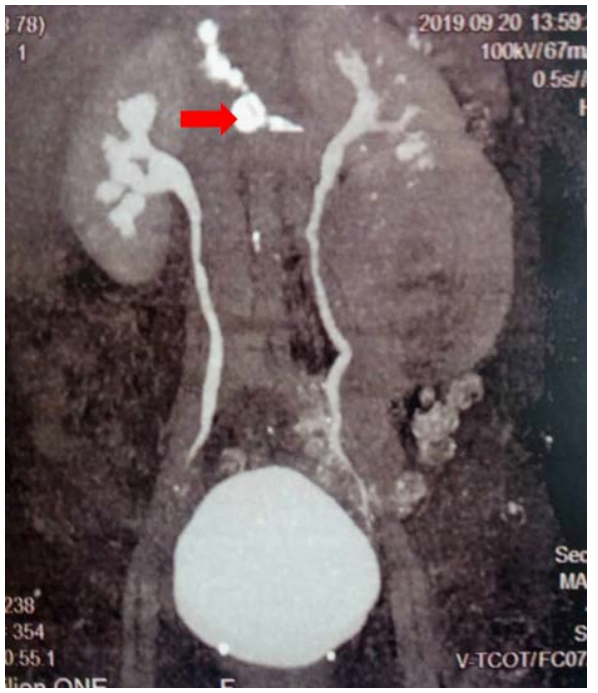

Figure 1. Computed tomography showing calcification in the IVC.

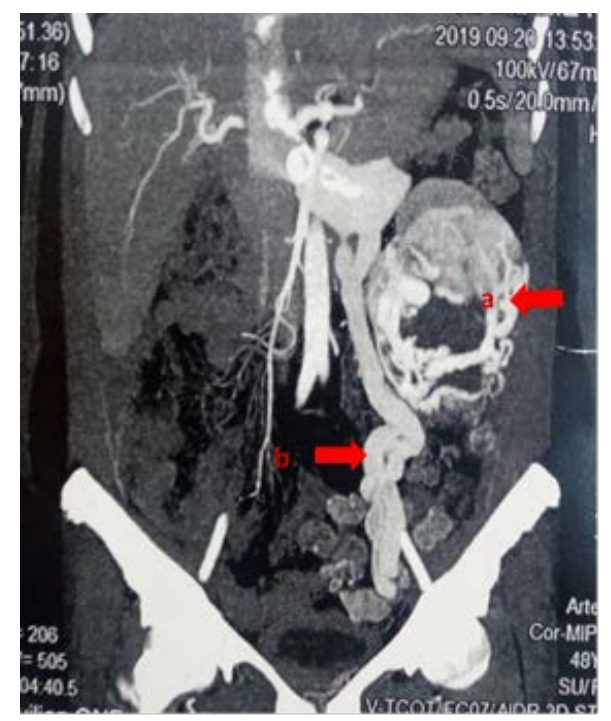

Figure 2. Computed tomography of the renal vessels showing. (a) A hypervascular lower pole tumor of the left kidney; (b) A dilatation of the left gonadal vein.

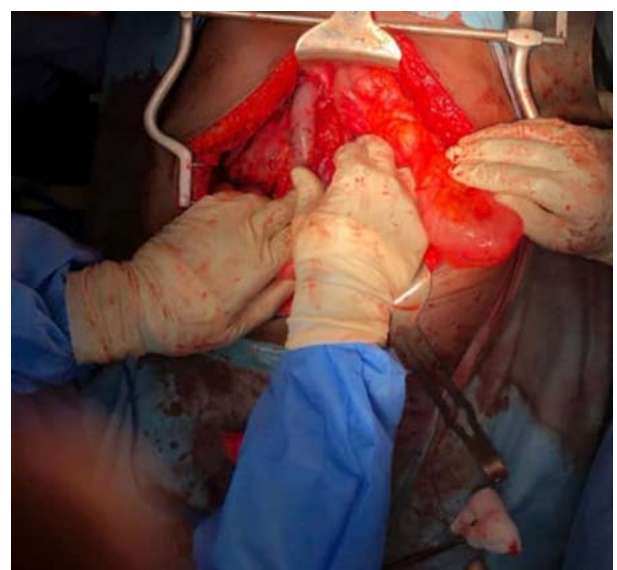

Figure 3. Right toldt fascia detachment. 
Medical loops were placed around the sub-renal and supra-renal portion of the IVC respectively, but also on the right and left renal veins. After clamping the medical loops (subrenal IVC, right renal vein and then suprarenal IVC) we performed a cavotomy with a cold scalpel and extracted the calcification (Figure 4). The suture of the IVC was performed with 5-0 non-adsorbable suture. We then did the extended left nephrectomy (Figure 5).

\section{Discussion}

The presence of a renal tumor can usually be correlated with a vena cava thrombus. In our context, CT scan is systematically requested in the assessment of operability of kidney tumors. This is an unprecedented situation as no similar case has been reported in Côte d'Ivoire.

Renal cancer with tumor thrombus is uncommon $(2 \%-10 \%)$. The largest cohort in Europe was reported by Manceau and involved 97 patients. This team has 30 years of experience in surgery in renal cancer with thrombus. Its mortality and morbidity were significant [2]. The first observations of calcification of IVC thrombus were described by Morgagni, on autopsy series, about 1769. These early descriptions were made on abdominal images. The classic appearance is a bullet-shaped calcification [3].

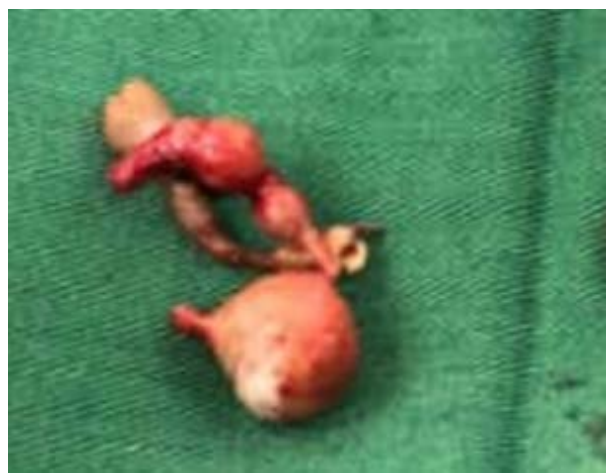

Figure 4. Calcification of the IVC.

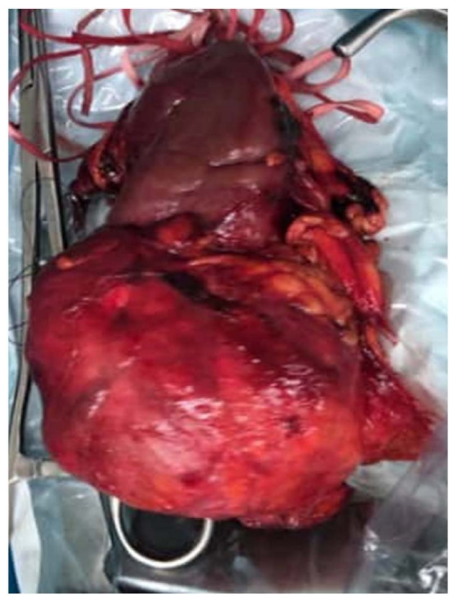

Figure 5. Tumor of the inferior pole of the left kidney. 
The surgical management of this type of cancer implies removal of the thrombus. It is therefore important to locate the exact level of the top of the thrombus. For this purpose, the Mayo classification is useful to assess the level of the thrombus. According to this classification, there are five levels. Level 0 , thrombus extending to the renal vein only; level I, thrombus extending into the IVC to no more than $2 \mathrm{~cm}$ above the renal vein; level II, thrombus extending into the IVC to more than $2 \mathrm{~cm}$ above the renal vein but not to the hepatic vein; level III, thrombus extending into the IVC to above the hepatic vein but not to the diaphragm; and level IV, thrombus extending into the supradiaphragmatic IVC or right atrium.

In our patient, the IVC thrombus was suspected on the computed tomography scan. The hyperdensity of the upper pole of this thrombus made us doubt the real nature. It was a level III thrombus according to the Mayo classification (Figure 6) [4]. The location of the top of the thrombus is so important that it may be necessary to use MRI for that.

There is no general consensus or guidelines for the treatment of this condition. In general, long-term anticoagulation has been recommended for patients with symptoms of pulmonary embolism or systemic embolization [5]. In our case, the anticoagulant treatment was started immediately preoperatively at a curative dose on the instruction of the cardiologist and stopped 48 hours before the surgical procedure.

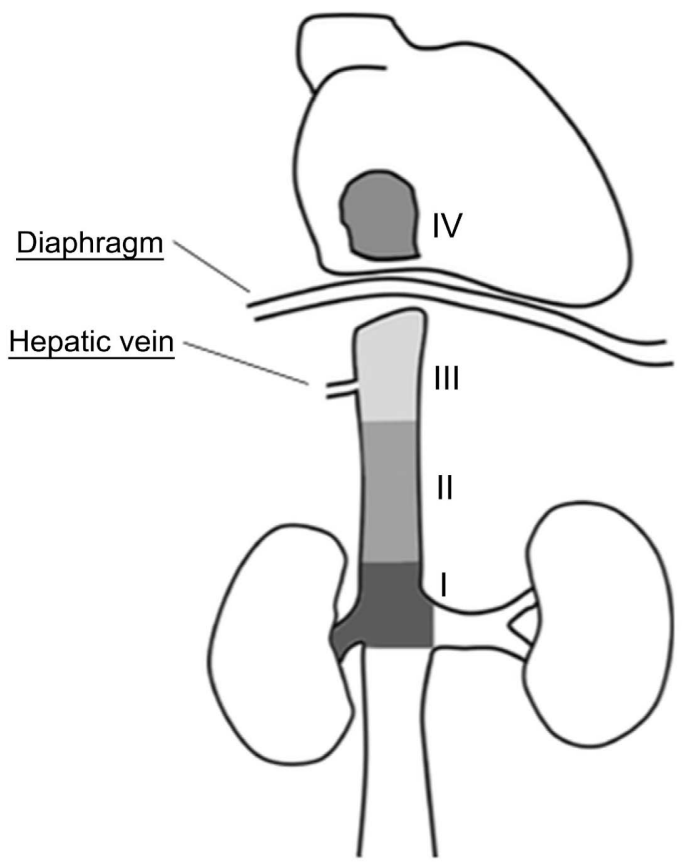

Figure 6. Classification of tumor thrombus level according to the Mayo staging system. Level 0 , thrombus extending to the renal vein only; level I, thrombus extending into the IVC to no more than $2 \mathrm{~cm}$ above the renal vein; level II, thrombus extending into the IVC to more than $2 \mathrm{~cm}$ above the renal vein but not to the hepatic vein; level III, thrombus extending into the IVC to above the hepatic vein but not to the diaphragm; and level IV, thrombus extending into the supradiaphragmatic IVC or right atrium [4]. 
The tumor can be approached via a different way. It can be a flank, sub-costal or midline incision. We performed an abdominal midline incision for a wide access to the kidney and the IVC. Control of the IVC is the first step in this surgical management to avoid inadvertent migration. We did not have to mobilize the liver. After venous control and cavotomy, thrombectomy with dissecting forceps was easy due to the solid character of the thrombus. It is important to put the clamp on the IVC above the top of the calcification to avoid any wound to the IVC and have effective vascular control. The calcification was addressed electively to reduce blood loss. Opening the IVC just as needed allows a quick suture after removal of the calcification and consequently a quick removal of the vascular clamps.

Aggressive surgical management for this condition is proposed by some authors. It allows a possible cure. This surgery is clearly difficult, and the outcomes can be discouraging regarding the percentage of mortality and morbidity. But, doing nothing will worsen the outcomes. In Hatakeyama's study, the perioperative mortality rate in patients with ICV thrombus was $6.7 \%$. Two patients $(6 \%)$ developed perioperative complications of Clavien grade $\geq$ III, and there were no deaths within one month of surgery. In patients who received surgical management, the 5-year survival rate was 78\% [4]. Median survival time was significantly longer in patients who had surgical management [6] [7] [8]. These different authors demonstrate that this surgery is possible with good results. A more recent study showed a poor prognosis of renal cancer with IVC thrombus There was a link between surgical complications and hospital stay [2]. It is important to give clear details of the case to the patient and his family. The definitive choice is guided by the patient's choice and the multidisciplinary team's decision. If a surgical option is selected, it has to be well prepared. In that case, neoadjuvant therapy using molecular-targeting agents is useful to improve the results [4].

\section{Conclusion}

The prognosis of kidney tumor with IVC thrombus is poor and associated calcification remains exceptional. The prognosis is poor, however, some studies have demonstrated an improvement in the prognosis by surgical treatment.

\section{Conflicts of Interest}

The authors declare no conflicts of interest regarding the publication of this paper.

\section{References}

[1] Leclerc, A., Lapebie, X., Thuillier, F. and Lacroix, P. (2016) Une calcification de la veine cave inférieure et de la veine rénale chez l'adulte. Journal des maladies vasculaires, 41, 294-297. https://doi.org/10.1016/j.jmv.2016.05.010

[2] Manceau, C., Porterie, J., Chaltiel, L., Gryn, A., Bellec, L., Roumiguie, M., Thoulouzan, M., Doumerc, N., Marcheix, B., Soulie, M., Grunenwald, E. and Beauval, J.B. (2018) Chirurgie du cancer du rein avec thrombus tumoral de la veine cave inférieure: 
la plus grande série européenne, avec 30 ans d'expérience au sein d'un centre expert. Progrès en Urologie, 28, 627-628. https://doi.org/10.1016/j.purol.2018.07.037

[3] Singleton, E.B. and Rosenberg, H.S. (1961) Intraluminal Calcification in the Inferior Vena Cava. American Journal of Roentgenology, 86, 556-560.

[4] Hatakeyama, S., Yoneyama, T., Hamano, I., Murasawa, H., Narita, T. and Oikawa, M. (2013) Prognostic Benefit of Surgical Management in Renal Cell Carcinoma Patients with Thrombus Extending to the Renal Vein and Inferior Vena Cava: 17-Year Experience at a Single Center. BMC Urology, 13, Article No. 47. https://doi.org/10.1186/1471-2490-13-47

[5] Iyer, P., Shrestha, R. and Zaman, M. (2017) Calcified Thrombus of Inferior Vena Cava in Adults: A Rare Entity. Chest Journal, 152, A602.

https://doi.org/10.1016/j.chest.2017.08.634

[6] Zisman, A., Wieder, J.A., Pantuck, A.J., Chao, D.H., Dorey, F., Said, J.W., Gitlitz, B.J., Dekernion, J.B., Figlin, R.A. and Belldegrun, A.S. (2003) Renal Cell Carcinoma with Tumor Thrombus Extension: Biology, Role of Nephrectomy and Response to Immunotherapy. The Journal of Urology, 169, 909-916.

https://doi.org/10.1097/01.ju.0000045706.35470.1e

[7] Miyake, H., Terakawa, T., Furukawa, J., Muramaki, M. and Fujisawa, M. (2012) Prognostic Significance of Tumor Extension into Venous System in Patients Undergoing Surgical Treatment for Renal Cell Carcinoma with Venous Tumor Thrombus. European Journal of Surgical Oncology, 38, 630-636. https://doi.org/10.1016/j.ejso.2012.03.006

[8] Staehler, G. and Brkovic, D. (2000) The Role of Radical Surgery for Renal Cell Carcinoma with Extension into the Vena Cava. The Journal of Urology, 163, 1671-1675. https://doi.org/10.1016/S0022-5347(05)67517-9 